\title{
O COMPROMISSO FORMATIVO NA AVALIAÇÃO DA APRENDIZAGEM EM QUÍMICA
}

\section{COMMITMENT IN FORMATIVE EVALUATION OF LEARNING IN CHEMISTRY}

\section{LA FORMACIÓN DEL COMPROMISO EN LA EVALUACIÓN DEL APRENDIZAJE EN QUÍMICA}

\author{
Elaine Cristina Galvão \\ *Professora do Quadro Próprio do Magistério da Secretaria de Educação do Estado \\ do Paraná, Participante do Programa de Desenvolvimento Educacional \\ Nadia Aparecida de Souza \\ ** Professora associada da Universidade Estadual de Londrina; Professora convidada \\ na Universidade Tecnológica Federal do Paraná
}

Resumo: O objetivo com esta pesquisa qualitativa foi mapear e analisar práticas avaliativas marcadas pelo compromisso formativo, detendo-se nas relações possíveis de serem estabelecidas entre elas e na maneira de abordar o erro, por parte dos professores de Química. Participaram três professoras de diferentes instituições da Rede Pública Estadual do Município de Londrina, PR. Os dados, recolhidos por meio de observação e entrevista semiestruturada, foram submetidos à análise de conteúdo temática. Os resultados revelaram que as professoras realizam práticas avaliativas formativas, intentando conhecer a estratégia empreendida pelo aluno para, pela recomposição do ensino, auxiliá-lo a avançar no processo de construção do conhecimento, bem como, que o erro passou a ser compreendido como um elemento essencial no processo de ensino e aprendizagem, sendo fonte de reflexões e descobertas.

Palavras-chave: Ação docente. Avaliação da aprendizagem. Ensino de Química. Erro. Regulação da aprendizagem.

Abstract: With this qualitative research it was aimed to map and analyze formative assessment practices marked by commitment, stopping at the potential relations to be established between them and the in way to approach the error, by Chemistry teachers. Three teachers from different institutions that make up the State Public Network in Londrina, PR participated. The data, collected through observation and semistructured interviews, were subjected to thematic content analysis. The results 
revealed that teachers perform formative assessment practices, attempting to know the strategy undertaken by the student to, by, the rebuilding of the school, help him advance in the knowledge construction process, as that well as the error came to be understood as an essential element to the teaching and learning process, being the source of reflections and discoveries.

Keywords: Teacher action. Assessment of learning. Chemistry teaching. Error. Pedagogical intervention.

Resumen: El objetivo de la investigación cualitativa fue mapear y analizar las prácticas de evaluación marcaron el compromiso formativo, parando las posibles relaciones que se establezcan entre ellos y la manera de abordar el error, por los profesores de la química. Participaron tres profesores de diferentes instituciones de la Red Pública del Estado en Londrina-PR. Los datos recogidos a través de la observación y entrevistas semiestructuradas fueron sometidos a análisis de contenido temático. Los resultados mostraron que los profesores llevan a cabo las prácticas de evaluación formativa, con la intención de conocer la estrategia emprendida por el estudiante a la reconstrucción de la educación, ayudan a avanzar en el proceso de construcción del conocimiento, así, el error llegó a ser entendido como un elemento esencial en el proceso de enseñanza y aprendizaje, una fuente de reflexiones y descubrimientos.

Palabras clave: Acción docente. Evaluación del aprendizaje. La enseñanza de la química. Error. Aprender regulación.

\section{ALGUMAS RAZÕES}

No decorrer dos anos, o ensino de Química tem resguardado abordagens mais tradicionais, geralmente centradas na memorização de fórmulas, reações e propriedades dos elementos, bem como na aplicação de regras e conceitos matemáticos, que são apresentados separadamente, fora do contexto de vida dos alunos, sem "[...] relacioná-los com a forma natural como ocorrem na natureza." (FARIAS; BASAGLIA; ZIMMERMANN, 2009, p. 2).

Balizado pelo modelo tradicional de educação (KOSSEBOEHMER; FERREIRA, 2008; LEAL, 2003; SCHNETZLER; NIEVES; CAMPOS, 2006; ZANON; OLIVEIRA; QUEIROZ, 2009), no qual se acredita que para ensinar basta ter domínio do conteúdo específico e valer-se de algumas técnicas pedagógicas, preferencialmente aquelas voltadas para a comunicação oral ou escrita, o ensino de Química tem se caracterizado pela supervalorização dos conteúdos curriculares e pela transmissão como 
método de ensino (MACENO; GUIMARÃES, 2013; SCHNETZLER; ARAGÃO, 1995). Essa concepção coloca o professor no centro do processo de ensino-aprendizagem, como grande detentor do conhecimento e fonte única do saber. O aluno, por sua vez, é sujeito passivo, cumprindo a ele se apropriar de grandes quantidades de conteúdo, de forma meramente receptiva e individualizada.

Em uma escola que se apresenta, a cada dia, mais isolada e à margem das mudanças a envolverem a sociedade atual, o ensino de Química se apresenta descontextualizado cultural, histórica e socialmente. As alternativas pedagógicas, evocadas em sala de aula, para sua efetivação, priorizam os aspectos quantitativos do processo. Há pouco espaço para a promoção de variabilidade didática: proposição de questionamento, realização de discussão, efetivação de trabalhos em grupo, desenvolvimento de projetos integradores, entre outras possibilidades. Isso acaba por fazer com que o corpo de conhecimentos seja apresentado de forma desarticulada, repetitiva e limitada (SANTOS JUNIOR; MARCONDES, 2010).

Superar a concepção de ensino-aprendizagem voltada para a transmissão/ assimilação ainda constitui um grande nó entre aqueles a ministrarem a disciplina, refletindo diretamente na avaliação da aprendizagem. O modelo avaliativo predominante verifica o desempenho do aluno mediante a aplicação de testes, em situações padronizadas, a demandarem a singela repetição do que já foi dito e reiterado, tantas e tantas vezes, durante as aulas (ZANON; OLIVEIRA; QUEIROZ, 2009; SCHNETZLER; ARAGÃO, 1995). Valorizam-se apenas os acertos para a consignação da nota, a qual é indicativo da aprendizagem, sendo atribuída aos erros, pouca ou nenhuma importância.

De acordo com Tacoshi e Fernandes (2008), é necessário romper com os paradigmas que conferem ao professor a tarefa de atribuir notas e ao aluno o dever de obedecer cegamente às regras que lhe são impostas. O processo avaliativo precisa ser efetivado como algo mais amplo, de modo a ajudar o aluno em seu processo de construção do conhecimento pelo oferecimento de informações capazes de prover subsídios para o professor ajustar o ensino. Urge ultrapassar esse modelo e aperfeiçoar a avaliação de maneira a torná-la mais profícua, buscando assegurar melhores resultados qualitativos e quantitativos.

Uma avaliação em Química precisa, progressivamente, ganhar outro formato em sala de aula. Para conceber mudanças e tracejar possibilidades, antes se faz fundamental elucidar a questão: como se anunciam, tendo por baliza a abordagem do erro, as práticas avaliativas dirigidas pelo compromisso formativo entre professores de Química? Responder orientou a definição do objetivo geral: mapear e analisar 
práticas avaliativas marcadas pelo compromisso formativo, detendo-se nas relações possíveis de serem estabelecidas entre elas e na maneira de abordagem do erro, por professores de Química atuantes em nível médio no ensino público.

\section{SITUANDO O PERCURSO}

A abordagem qualitativa revelou-se mais apropriada para o desenvolvimento do estudo, pois considera "[...] o universo de significados, motivos, aspirações, crenças, valores e atitudes, o que corresponde a um espaço mais profundo das relações, dos processos e dos fenômenos que não podem ser reduzidos à operacionalização de variáveis." (MINAYO, 1994, p. 22). Ela permite compreender um fenômeno em toda a sua complexidade, respondendo a questões particulares, que não podem ser entendidas isoladas de seu contexto, a partir da perspectiva dos sujeitos da investigação (BOGDAN; BIKLEN, 1994; FLICK, 2004).

Desse modo, eleger a pesquisa qualitativa decorreu, em parte, do fato de o foco do estudo voltar-se para as vivências e experiências das professoras de Química, sendo necessário inserir-se em seu ambiente natural, para dele extrair os "significados visíveis e latentes" (CHIZZOTTI, 1998), a constituírem-se elementos fundamentais à compreensão do objeto de investigação. Ainda, o estudo particularizou-se por valer-se das palavras pronunciadas ou consignadas sobre o papel para descrever situações e momentos relevantes ao objeto de estudo, acatando um cuidado especial: respeitar a perspectiva dos participantes, no intuito de iluminar a "[...] dinâmica interna das situações, dinâmica esta que é frequentemente invisível ao observador exterior.” (BOGDAN; BIKLEN, 1994, p. 50).

O universo de pesquisa foi o ensino público, de nível médio, em três instituições localizadas na Cidade de Londrina, PR. Participaram três professoras, que primeiro consentiram formalmente em contribuir com a pesquisa, cada uma atuante em uma das escolas. Para a efetivação do estudo, foram selecionados dois instrumentos de coleta: entrevista para aprofundamento das concepções de avaliação da aprendizagem e erro e observação para acompanhar situações avaliativas e formas de abordagem do erro ocorridas no cotidiano escolar.

Os dados coletados foram lidos e submetidos à análise de conteúdo temática (BARDIN, 1979). Por isso, palavras e ações das professoras participantes foram agrupadas conforme convergências identificadas pela repetição das unidades de registro, que sofreram uma primeira aglutinação, resultando em subcategorias que, poste- 
riormente reunidas, compuseram as categorias de análise: (1) concepção formativa de avaliação da aprendizagem e suas implicações nas (2) formas de abordagem do erro.

\section{TESSITURAS DA AVALIAÇÃO DA APRENDIZAGEM EM QUÍMICA}

Em Química, no decorrer dos anos, tem predominado o ensino diretivo (BRITO; SANTANA; LOPES, 2010; COSTA et al., 2005; KOSSEBOEHMER; FERREIRA, 2008; PACCA; SCARINCI, 2012; TACOSHI; FERNANDES, 2008; TREVISAN; MARTINS, 2006 a revelar-se em práticas mais tradicionais e tecnicistas e a consubstanciar-se na perspectiva classificatória de avaliação da aprendizagem.

Sob a égide tradicional de ensino, o professor tem como certo ser o único a deter o conhecimento e, por isso, toma para si a tarefa de transmiti-lo aos alunos, que nada sabem, assemelhando-se a folhas de papel em branco. A relação professor-aluno perpetrada é unidirecional, ao manter o foco do processo centrado na figura do professor e a ênfase do ensino na transmissão de conteúdos prontos e inquestionáveis, apresentados como verdades absolutas (SILVA; MORADILLO, 2002; TREVISAN; MARTINS, 2006). Em decorrência, predominam as práticas pedagógicas conservadoras e reprodutivistas, calcadas na quietude e passividade do aluno, a quem cumpre realizar repetidos cálculos, utilizar e reutilizar fórmulas em situações similares, copiar símbolos, memorizar reações e nomenclaturas e reproduzir propriedades dos elementos químicos. Predomina o treino, pois não são estabelecidas relações com situações reais do cotidiano (CAVALCANTE; SILVA, 2008).

A aprendizagem é receptiva, garantida por um sistema de repetição e recapitulação constante da matéria. Mesmo as atividades experimentais são meramente demonstrativas, cabendo ao professor executá-las e explicá-las. Sua função é ilustrativa, ou, em determinadas situações, apenas servem para comprovar um conhecimento previamente ensinado (SCHNETZLER; NIEVES; CAMPOS, 2006). Os esforços dos alunos recaem, então, em dedicar atenção ao professor e valer-se de quaisquer mecanismos que os tornem capazes de repetir o ensinado.

Em uma perspectiva mais diretiva e tradicional, a ação avaliativa está impregnada de atributos orientados pela tríade transmissão/assimilação/reprodução, direcionando para a prática de exames, centrados na aferição, a subsidiar sucedâneas classificações e hierarquizações. Os instrumentos avaliativos são elaborados para se verificar o quão bem os conteúdos foram memorizados, porque propiciarão a repro- 
dução do ensinado (SANTOS JUNIOR; MARCONDES, 2010; LOPES, 1998; SCHNETZLER; ARAGÃO, 1995; SILVA, 1999).

Para avaliar, o professor utiliza a prova como principal instrumento, e ela, na maioria das vezes, contém questões a demandarem apenas o resgate da memória, propondo problemas a exigirem singela aplicação de fórmulas e realização de cálculos, reiteradamente treinados em sala de aula e a envolverem habilidades puramente operacionais (VILLATORRE; HIGA; TYCHANOWICZ, 2009). Além disso, normalmente, a prova é aplicada ao final de uma unidade de ensino, constituindo, numerosas vezes, o único meio para a coleta de informações quanto à aprendizagem do aluno.

Diferentes estudos destacam que, na disciplina de Química, tem predominado a perspectiva classificatória de avaliação da aprendizagem (LUCA, 2001; QUADROS et al., 2006; SANTOS; SCHNETZLER, 1996). Então, a nota assume caráter nodal, porque evidencia a aprendizagem do aluno e é indicadora inquestionável das condições para a sua aprovação ou retenção. Ao atribuí-la, o professor encerra o ato avaliativo, pois os interesses - de professores, familiares e alunos - limitam-se, geralmente, ao resultado final (SILVA; MORADILLO, 2002).

Estudos, como os desenvolvidos por Maldaner (2003), Trevisan e Martins (2006) e Tacoshi e Fernandes (2008), ou aqueles levados a termo por Santos e Schnetzler (1996) atestam essa realidade. Os dados colhidos por eles comprovam que, para a maioria dos professores de Química, a prova, realizada em momentos pontuais, normalmente ao final do bimestre, é a forma mais utilizada na aferição da aprendizagem. Em relação aos resultados não satisfatórios, o conteúdo é retomado a partir da realização de mais exercícios, semelhantes aos praticados em situações anteriores - quando não idênticos, porque exigem tão somente copiar e resolver a prova. O processo culmina com a aplicação de uma nova prova, não muito diversa da anterior. A elevação da nota é o seguimento aguardado.

Contudo, apesar de a avaliação em Química ainda se voltar para a classificação, vários pesquisadores (BROTERO, 2006; DAZZANI, 2004; SILVA; MAXIMIANO, 2010; TACOSHI; FERNANDES, 2008) têm se preocupado com a realização de uma avaliação orientada para a qualidade da aprendizagem. Estudos recentes revelam a disposição de alguns professores em desencadearem um processo educativo no qual a avaliação da aprendizagem constitua-se em um momento de contribuição para o desenvolvimento do aluno.

No estudo efetivado por Silva e Moradillo (2002), é apresentada uma proposta de trabalho, em Química, integrando ensino, aprendizagem e avaliação. Os autores descrevem a intencionalidade da proposta: inicialmente, a partir da experimen- 
tação, identificar as concepções prévias dos alunos a respeito dos principais conceitos a serem abordados, e a configurarem-se referência para o planejamento de ensino e o acompanhamento de mudanças conceituais ao longo do trabalho. O processo avaliativo ocorreu integrado ao ensino e à aprendizagem, pois, conforme as atividades eram propostas e desenvolvidas, propiciavam aos professores avaliar naturalmente à medida que os conhecimentos e posicionamentos iam sendo expostos pelos alunos.

Uma experiência expressiva também foi descrita por Silva e Maximiano (2010). O estudo apresenta a utilização de mapas e redes conceituais como ferramentas de avaliação no ensino de Química. Consoante o pesquisador, a estratégia é muito significativa para o processo de ensino-aprendizagem e avaliação, pois permite verificarem-se as relações que se estabelecem entre os conhecimentos prévios e os novos, bem como entre os diferentes conceitos químicos. Os resultados revelaram-se positivos no concernente à produção de mudanças nos procedimentos avaliativos comumente utilizados em sala de aula, visto que possibilitaram maior interação entre aluno/aluno e professor/aluno, favorecendo a aprendizagem.

Os estudos brevemente informados registram a prevalência classificatória na avaliação da aprendizagem em Química, mesmo que se principie no vislumbrar de algumas experiências - ainda tímidas - intentando conferir-lhe a conotação de processo investigativo compromissado com o aperfeiçoamento do processo de ensino e a melhoria da aprendizagem, pela superação progressiva dos problemas identificados.

\subsection{IMPLICAÇÕES DAS CONCEPÇÕES AVALIATIVAS NA ABORDAGEM DO ERRO}

Toda prática de avaliação que objetiva orientar o processo de ensino, a fim de contribuir para a melhora contínua do aluno em sua aprendizagem, é formativa (ABRECHT, 1994; AFONSO, 2000; ÁLVAREZ MÉNDEZ, 2002; BLOOM; HASTING; MADAUS, 1983; FERNANDES, 2008; HADJI, 1994, 2001; HOFFMANN, 1993, 2001, 2003, 2005; LUCKESI, 1995, 2005, 2011; PERRENOUD, 1999; RABELO, 1998; VASCONCELLOS, 2008; TEIXEIRA; NUNES, 2008). Sob esse olhar, a avaliação tem o propósito de ser um instrumento informativo quanto aos meandros por entre os quais ocorre a apropriação dos conhecimentos, com o intuito de oportunizar a planificação e implementação de propostas pedagógicas favoráveis ao seu desenvolvimento e à superação das suas dificuldades (ZABALLA, 1998).

O exercício de uma avaliação progressivamente mais formativa demanda assumi-la como momento de paragens, reflexões e reformulações, de tal modo que o 
propósito seja o de identificar as dificuldades de aprendizagem para transpô-las. Perrenoud (1999, p. 78) descreve como formativa toda "[...] prática de avaliação contínua que tem como objetivo principal melhorar as aprendizagens em curso", contribuindo para o acompanhamento e para a orientação dos alunos durante toda a formação. Para ele, a ação avaliativa centra seu foco na gestão da aprendizagem, sendo definida pelo acompanhamento constante da qualidade do processo de ensinar e de aprender, com vistas ao ajuste do ato pedagógico.

Na concepção de Hadji (2001, p. 19), essa modalidade de avaliação localiza-se “[...] no centro da ação de formação e sua função principal é contribuir para uma boa regulação da atividade de ensino." Destarte, avaliar é mais que provar a existência da aprendizagem, implicando uma ação indicativa dos progressos alcançados e das dificuldades enfrentadas pelo aluno ao longo de seu percurso de aprendizado.

Fernandes (2008), por sua vez, caracteriza como formativa a avaliação que é intencionalmente organizada para ajudar o aluno a aprender mais e melhor. O autor destaca que a avaliação formativa está a serviço da aprendizagem, pois utiliza a informação recolhida para planificar os passos seguintes da ação docente e criar novas possibilidades que permitam ao aluno desenvolver-se.

Na ótica de Hoffmann (1993, p. 18), avaliar formativamente suscita o olhar mais vigilante do professor, no sentido de uma "[...] reflexão permanente sobre sua realidade e um acompanhamento, passo a passo, do educando na sua trajetória de construção do conhecimento." Para a autora, observar o aluno mais atenta e metodicamente permite não somente compreender melhor como pensa e as formas que utiliza para aprender, mas, também, entender os problemas que dificultaram a efetividade do ensino e foram obstáculo para o alcance dos objetivos.

Em perspectiva semelhante, Luckesi $(2005$, p. 81) afirma que a avaliação da aprendizagem deve ser assumida como "[...] um instrumento de compreensão do estágio de aprendizagem em que se encontra o aluno, tendo em vista tomar decisões suficientes e satisfatórias para que se possa avançar no seu processo de aprendizagem." O intuito é que a avaliação se concretize como um procedimento diagnóstico de uma situação ou estado e que se efetive em favor do aluno, para subsidiar a tomada de decisões no sentido de ultrapassar os problemas constatados, sobrepondo-se, assim, aos aspectos meramente técnicos e constatatórios.

Percebe-se, nos apontamentos teóricos, certo consenso entre os autores citados. Para eles, avalia-se para compreender e explicar o processo de aprendizagem, para entender por qual motivo esse processo ocorreu de determinada maneira, para identificar seus problemas e avanços e tracejar caminhos favoráveis à progressão. 
Mais ainda, a avaliação pode servir, antes de tudo, como uma possibilidade de reflexão permanente, tanto por parte do professor quanto por parte dos alunos.

Sob a perspectiva das participantes deste estudo, a compreensão de que a avaliação deve deixar de girar exclusivamente em torno do rendimento do aluno começa a ser descortinada, conforme expressam as professoras:

Eu vejo a avaliação como uma forma de saber se o que você está falando lá na frente, o que está ensinando, se está sendo compreendido pelos alunos. Também é pela avaliação que se consegue identificar aqueles alunos que têm dificuldades e daí pensar como trabalhar com eles. (P1).

A avaliação é um momento para você saber se vai avançar com os conteúdos ou se você volta e trabalha mais um pouco, porque os alunos estão apresentando dificuldades. Na sala de aula, o professor precisa estar atento, pois avaliação não é só o que o aluno escreve no papel e lhe entrega, mas é tudo o que ele realiza ali dentro. (P2).

Para mim, a avaliação serve para eu saber se os meus alunos aprenderam determinado conteúdo e, também, para ver se consegui passar esse conteúdo de forma clara, compreensível para eles. Quando eu cobro um conteúdo numa prova, por exemplo, e vejo que os alunos tiveram dificuldade, então alguma coisa está errada. Vou ter que rever e abordar novamente esse conteúdo de uma forma diferente. (P3) (informações verbais).

Os relatos evidenciam que as três professoras compreendem a avaliação como um momento de deter-se para proceder uma leitura acerca do andamento do processo de ensino- aprendizagem. Elas descrevem a avaliação como uma bússola, capaz de permitir-lhes mapear as aprendizagens em curso e identificar as dificuldades ainda presentes. Mais do que obter informações para transformar acertos e erros em notas, seu exercício acontece, preferencialmente, no sentido de apontar as falhas no processo, as aprendizagens ainda não alcançadas e os aspectos a serem melhorados, a fim de subsidiar uma tomada de decisão que lhes possibilite ajudar o aluno a avançar em seu percurso de aprendizagem.

Há demonstração, ainda, de uma preocupação com o redimensionamento da ação docente, indicativo de que a avaliação constitui um momento oportuno para avaliar o trabalho levado a termo por elas, em relação ao desenvolvimento dos alunos (DEPRESBISTERIS, 1999; LUCKESI, 2011; MOREIRA, 2005). Nota-se um estado orientado para a adequação do ensino, de forma a propiciar a operacionalização de situações favoráveis à aprendizagem, ajustando as intervenções aos obstáculos que se apresentam.

P2 expressou uma compreensão mais ampla da questão ao afirmar: "[...] a avaliação não é só o que o aluno escreve no papel e lhe entrega, mas é tudo o que ele 
realiza ali dentro, na sala de aula." (informação verbal). Ao declarar que a avaliação acontece frequentemente, por meio da captação de informações no decorrer do trabalho cotidiano, em sala de aula e em diferentes momentos do processo de ensino, revela entender a importância do caráter processual da avaliação e de sua integração ao fazer diário do professor, que deverá potencializar, quando necessário, o ajuste do processo.

Percebe-se um entendimento que ultrapassa os aspectos formais da aferição. A professora ressalta a importância de estar atenta às manifestações dos alunos em sala de aula, pois estas estão impregnadas de significados que fornecem informações valiosas em relação à progressão das aprendizagens (HOFFMANN, 2001).

De maneira geral, suas palavras e ações revelam estar muito mais preocupadas em acompanhar o processo de construção e apropriação do conhecimento pelos seus alunos do que em verificar o quão bem retiveram conteúdos que lhes foram transmitidos. Ainda, ao corrigirem as atividades avaliativas, não têm suas ações dirigidas pela necessidade exclusiva de produzir uma média - apesar de as notas serem uma realidade a ser respeitada no interior das escolas, até pela força da legislação vigente -, mas procuram mapear os objetivos não atingidos, os aspectos falhos, as lacunas de aprendizagem. Ao assim procederem, não são direcionadas pelo registro do escore e prosseguimento na proposição do conteúdo, mas pelo compromisso com o desencadeamento de intervenções que almejam a superação dos problemas identificados (Esquema 1).

Esquema 1 - Caracterização dos elementos constitutivos de avaliação da aprendizagem atribuídos por P1, P2 e P3

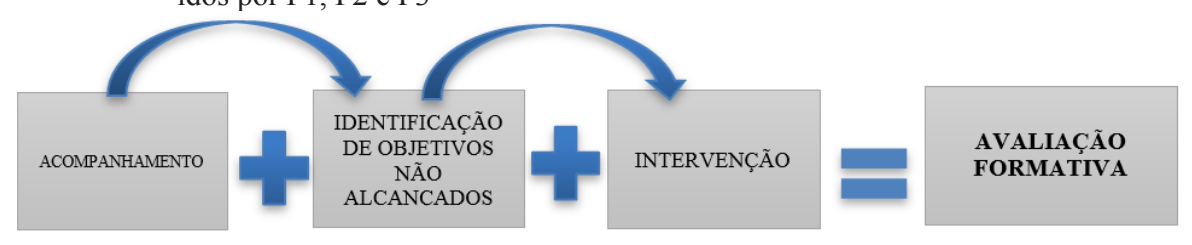

Fonte: os autores.

Todavia, as três professoras expõem que avaliar formativamente é um esforço grande a exigir-lhes muito, principalmente considerando-se as condições de trabalho prevalecentes no contexto escolar. É preciso ensinar articulando os conteúdos à realidade do aluno, cumprir o programa de ensino da disciplina com um número reduzido de horas-aula, garantir o envolvimento nas atividades do maior número possível de alunos, manter a disciplina de modo que a convivência em sala de aula seja agradável e pacífica, elaborar atividades estimulantes e provocativas, cumprir as exigências legais do sistema e os prazos estabelecidos pela instituição, trabalhar com tur- 
mas compostas por número excessivo de alunos, etc. É natural pensar que todos esses elementos acabem, de certo modo, por influenciar a ação avaliativa das professoras.

No entanto, mesmo em meio às muitas dificuldades, seguir de perto o que aconteceu na sala de aula revelou uma prática avaliativa voltada muito mais para o acompanhamento e para a orientação das ações educativas do que para a composição de escores de rendimento. A investigação mostrou haver professoras que contrariam as ações presas à lógica tradicional, com fins exclusivamente classificatórios, pois o modo de agir de P1, P2 e P3 indica que tencionam criar condições para que o aluno aprenda (o que se descreve nas Cenas 1, 2, 3, 4 e 5 apresentadas nos Quadros 1, 2, 4, 6 e 7).

Quadro 1 - Descrição de situação avaliativa de P1

Cena 1: Dia de prova. A professora inicia a aula pedindo aos alunos para organizarem as carteiras em fila e guardarem todo o material, deixando sobre a carteira somente caneta, lápis e borracha. Em seguida, orienta para que leiam atentamente as questões antes de iniciarem a resolução. Explica que realizarão a prova sem o seu auxílio e diz que, para cada questão, há somente uma alternativa correta. Orienta, ainda, que os cálculos relativos às questões sejam feitos na folha de prova, não devendo ser descartados.

Então, as folhas de prova são distribuídas para todos os alunos, e a professora inicia a leitura das questões. A leitura de cada uma das questões é seguida pela explicação acerca de como cada exercício deve ser resolvido. Ao concluir, P1 sinaliza para que os alunos iniciem a realização da prova. Depois disso, a professora dirige-se ao quadro de giz e anota duas fórmulas, para as quais chama a atenção dos alunos, dizendo que serão aquelas as fórmulas necessárias para a resolução dos exercícios da prova.

Durante a aplicação da prova, cujo conteúdo tratava dos cálculos termoquímicos, a professora apenas observa os alunos. Em dado momento percorre a sala de aula, porém não realiza nenhum tipo de apontamento ou intervenção.

$\mathrm{Na}$ aula seguinte a professora entrega as provas, chamando os alunos um a um pelo nome, e explica que realizará a correção das questões da prova, resolvendo-as no quadro de giz. Antes de iniciar, P1 diz que os resultados foram muito ruins e, por isso, durante a correção retomará alguns conceitos do conteúdo e esclarecerá dúvidas. A correção ocorre inicialmente pela leitura do enunciado, no qual a professora enfoca dados relevantes, registrando-os no quadro de giz. Enquanto procede a resolução da questão, recupera partes do conteúdo e realiza perguntas estimulando a participação dos alunos.

As perguntas realizadas pela professora são objetivas e, na maioria das vezes, requerem respostas diretas que envolvem recordar dados ou procedimentos e não exigem domínio aprofundado do conteúdo. Outras vezes, usa expressões como: “O que eu quero saber aqui? Qual é a pergunta do problema?", "Todo mundo entendeu isto?” ou "A resolução do exercício para por aqui? O que devemos fazer a seguir?" P1 prossegue com a aula dessa maneira, resolvendo as questões e os alunos anotando as respostas corretas. A aula chega ao fim e a professora diz que continuará a correção num próximo momento.

Fonte: os autores. 
Na Cena 1, P1 atua formativamente, pois, ao detectar pontos frágeis da aprendizagem, interfere de maneira consciente e deliberada em favor da remoção das dificuldades a obstaculizarem o domínio dos conhecimentos. Ela se vale do instrumento avaliativo para coletar dados que subsidiam suas reflexões e ações: analisar a efetividade do ensino, identificar problemas de aprendizagem e conceber ações de superação.

P1 expressa inquietação em ajustar o processo de ensino-aprendizagem. Ela revela entender que o papel da avaliação é, inicialmente, identificar os elementos que atravancam a aprendizagem, para, em seguida, subsidiar e orientar "[...] intervenções criticamente informadas.” (ÁLVAREZ MÉNDEZ, 2002, p. 76). O professor não pode ficar insensível aos resultados, facultando, diante deles, redirecionar o seu trabalho, auxiliando o aluno na superação das dificuldades, favorecendo seguir uma nova trajetória, pois de nada adianta “[...] levantar problemas e pensar sobre eles sem nada realizar [...]" (SOUZA; BORUCHOVITCH, 2009, p. 208).

A abordagem dos erros foi realizada a posteriori, tendo por baliza os erros identificados na atividade avaliativa. Para realizar a intervenção, P1 destinou toda uma aula, no decorrer da qual os momentos de resolução das questões, no quadro de giz, foram permeados pelo questionamento e pelo diálogo. Ela se mobilizou para auxiliar os alunos a desfazerem suas dificuldades. Ao decidir pela retomada do conteúdo, P1 indica compreender que "[...] o processo de aprendizagem do aluno não segue percursos programados a priori pelo professor.” (informação verbal). É preciso retomar quando necessário, é fundamental investir tempo para que o aluno aprenda, pois não traz vantagem impor um ritmo acelerado à apresentação dos conteúdos, se aquele que deveria apreendê-los não está sendo beneficiado, se está "ficando para trás".

Na sequência, P1 relata: "[...] depois de realizar a atividade, eu sempre trago um feedback para os alunos. Geralmente, tento fazer isso na aula seguinte, para não ficar muito distante e o trabalho estar bem fresco na cabeça deles." (informação verbal). A professora declara compreender a importância de promover uma devolutiva, na qual seja possível ao aluno reconhecer as suas falhas ou as razões da incompletude do trabalho. Assim, ela procede na aula seguinte, quando devolve os relatórios para os alunos e, com eles, retoma as atividades no quadro de giz.

P1 revela ter nas atividades avaliativas uma fonte de informações que elucidam as aprendizagens já alcançadas e aquelas ainda em curso. Contudo, mais que proceder ao diagnóstico das dificuldades, ela deixa entrever a sua preocupação em assistir aos alunos, criando condições favoráveis a prosseguirem aprendendo. Todavia, ao intervir no curso do processo, ela o faz corrigindo os erros pela apresentação da resposta certa, do padrão a ser seguido como modelo (Quadro 2). Em decorrência, 
os diferentes percursos de aprendizagem são ignorados, uma vez que todos precisam empreender os mesmos passos, no mesmo ritmo, pela mesma estrada.

Figura 2 - Caracterização da prática avaliativa de P1

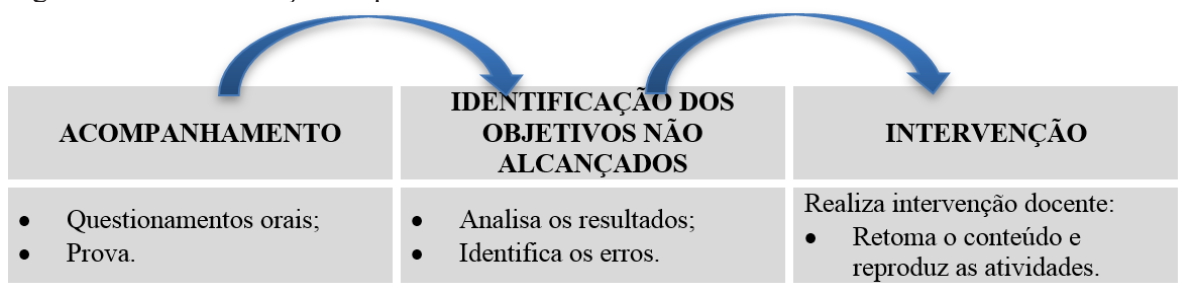

Fonte: os autores.

Quadro 3 - Descrição de situação avaliativa de P2

Cena 2: A professora inicia dizendo que nessa aula será realizada uma tarefa valendo nota, abordando o conteúdo Ligações Químicas. Em seguida, entrega a cada aluno uma folha contendo seis exercícios e pede que realizem a atividade individualmente, utilizando os registros constantes no caderno para consulta, se necessário. Depois disso, a professora orienta que, antes da resolução, realizem a leitura de todas as questões. Então pergunta: "É necessário explicar os exercícios?" Os alunos não respondem, pois já estão envolvidos na resolução da atividade. Ela se dirige à sua mesa e faz anotações no livro de registro de classe. Por vezes, observa a turma, porém, sem interferir. Os alunos trabalham em silêncio e, ao concluírem a atividade, entregam-na à professora e são dispensados para o intervalo.

Nesse dia a professora tem um intervalo entre as aulas e faz a correção da atividade.

Ao retornar à sala de aula, $\mathrm{P} 2$ registra no quadro de giz duas questões da atividade. Em seguida, pergunta aos alunos: "Vocês tiveram dificuldade para resolver estas questões?" e obtêm vários acenos positivos por parte deles. A professora inicia a resolução das duas questões. Enquanto resolve os exercícios, P2 faz perguntas simples, geralmente relativas à próxima etapa da resolução da questão, de forma a retomar a exposição do conteúdo. Concluída a correção, as folhas da atividade são devolvidas aos alunos. P2 orienta-os para que comparem as suas respostas com a resolução constante no quadro, a fim de identificarem o ponto em que ocorreu o erro.

P2 então se dirige ao quadro e registra outras duas questões, semelhantes àquelas resolvidas. Depois solicita aos alunos que copiem em folha separada, que as resolvam e entreguem, pois serão reavaliados relativamente às questões e terão a nota substituída, prevalecendo a maior nota. Fonte: os autores.

$\mathrm{Na}$ Cena 2, P2 revela-se, aparentemente, enredada pelas perspectivas avaliativas classificatória e formativa. O cenário descrito transmite imagem bastante comum no ambiente escolar: alunos centrados na execução do teste, enquanto o professor observa. A um olhar desatento, a ação e a postura assumidas remetem à prática da avaliação classificatória, porém, o desenrolar de toda a cena denuncia o exercício de uma compreensão mais formativa de avaliação da aprendizagem. 
Ao distribuir a prova, P2 preocupa-se em orientar os alunos na resolução, pede-lhes para lerem todas as questões, coloca-se à disposição para responder às perguntas e auxiliar em caso de dúvidas. Mesmo no decorrer da resolução das questões, ela observa o andamento da atividade, para interferir se for preciso, conforme esclarece: “[...] enquanto os alunos trabalham, procuro ficar atenta. Dá para perceber quando eles estão precisando de ajuda, então é hora de agir!” (informação verbal). P2 procura oferecer o apoio necessário à aprendizagem - mesmo no momento da prova. Portanto, ela promove o acompanhamento, empreendendo esforços para que a aprendizagem se concretize.

Durante a hora atividade, a intercalar as duas aulas com a turma naquele dia, P2 corrige as atividades dos alunos, realizando anotações em folha à parte. Convidada a explicar a finalidade das anotações, P2 esclarece: “As notas foram boas, em sua maioria, mas eu sempre costumo anotar quais foram as questões que os alunos mais erraram, quais as dificuldades mais frequentes, para poder revê-las com eles." (informação verbal).

Ribeiro (2011, p. 85) destaca que uma ação formativa “[...] requer ser pensada e, muitas vezes, repensada pelo professor", entendimento demonstrado por P2 ao declarar: “[...] em sala de aula não é só jogar o conteúdo e pronto. É preciso pensar a respeito de como os meus alunos estão aprendendo e analisar também a minha própria aula, a forma como estou ensinando." (informação verbal). A afirmação revela a assunção de que, na ação educativa, manter uma postura reflexiva é fundamental para que adaptações e ajustes possam ser implementados para que o aluno evolua, constantemente, em sua aprendizagem. 
Quadro 4 - Descrição de situação avaliativa de P2

Cena 3: Nessa aula, a professora apresenta um vídeo curto, de aproximadamente 12 minutos acerca do conteúdo de Química Orgânica: feromônios. Concluída a apresentação, P2 pergunta aos alunos se conseguiram entender o que é um feromônio. Os alunos apresentam diferentes respostas enquanto a professora apenas acena positivamente com a cabeça. Em seguida, P2 explica que feromônio é uma substância Química secretada, no ambiente, por insetos e mamíferos e que age como atraente sexual ou como marcador de trilhas.

A professora usa as formigas como exemplo. Elas costumam seguir em fila porque são atraídas por um determinado tipo de feromônio. Os alunos riem, porque uma das meninas da turma diz já ter usado outro tipo de feromônio, mas não para atrair formigas. Em seguida, P2 utiliza uma série de slides, contendo diferentes imagens de animais e o nome do feromônio produzido por cada um deles. Usa o exemplo da mariposa, que produz um tipo de feromônio para atrair o macho. À medida que vai apresentando as imagens nos slides, também exibe a fórmula estrutural dos compostos. Depois disso, P2 registra no quadro de giz a fórmula de três diferentes compostos e pede para que os alunos observem, identificando as semelhanças entre elas. Os alunos se arriscam e a professora vai anotando as respostas no quadro. A seguir, ela inicia a explicação das principais características dos feromônios, apresentando nas fórmulas químicas algumas delas. Ao concluir, P2 se volta para as respostas atribuídas pelos alunos e pergunta: “Então, vamos ver o que vocês acertaram?" Para cada resposta, a professora pergunta: "É uma característica dos feromônios?", e em seguida, marca um C para as respostas certas e um X para as erradas. Finalizada a análise das respostas, P2 solicita aos alunos que elaborem um texto, contendo aproximadamente 10 linhas, no qual expressem o que entenderam em relação do conteúdo. Ela explica que a essa atividade será atribuída uma nota e que o conteúdo do texto deve contemplar aspectos como: uma definição de feromônio; alguns exemplos de feromônios; a função da substância química; outras informações que chamaram a atenção dos alunos. Fonte: os autores.

P2, na Cena 3, organiza a sequência didática de maneira a ensinar e avaliar concomitantemente. O diálogo, trazido para o centro do processo de ensino-aprendizagem, permitiu colher valiosas informações a respeito da aprendizagem em construção. $\mathrm{Na}$ aula, foram utilizados e explorados diferentes recursos: apresentação de vídeo, questionamentos orais, exposição dialogada, e apresentação de slides referentes ao tema em estudo. O intuito, segundo P2 relata, é respeitar a diversidade dos modos de aprender, a mesclarem-se no interior da sala de aula, bem como oportunizar a explicitação de dúvidas, questionamentos e equívocos, de maneira a elucidar incertezas e responder às necessidades. Assim, ao diagnosticar as falhas no processo, P2 deliberadamente interfere, conduzindo os alunos à identificação dos erros e à (re)construção do saber. Nessa perspectiva de entendimento, o erro "[...] representa um indício, entre muitos outros, do processo de construção de conhecimentos." (ESTEBAN, 2003, p. 22). As respostas, certas ou erradas, constituem um processo em constante construção a indicar um saber ainda provisório (ABRAHÃO, 2004) e, portanto, sempre possível de ser aperfeiçoado. 
Ao se analisarem as respostas, a preocupação se volta para o alcance dos objetivos, intentando compreender as razões a ensejarem desvios e dificuldades.

A cena revela que a avaliação da aprendizagem não se limita a um tempo demarcado pelo dia e pela hora da prova. Na verdade, evidencia o exercício constante da prática avaliativa no decorrer de toda a aula. P2 coleta informações pela observação, pelo diálogo e pela análise de tarefas, demonstrando o entendimento de que a finalidade da ação avaliativa é o acompanhamento contínuo dos progressos dos alunos, bem como dos possíveis erros e dificuldades, pretendendo intervir e assegurar avanços. Assim, os dados obtidos nas tarefas avaliativas são objeto de reflexão e subsidiam ações sucedâneas, concebidas e desencadeadas de maneira intencional e fundamentada, garantindo a presença da terceira característica - a intervenção (Quadro 5).

Quadro 5 - Caracterização da prática avaliativa de P2

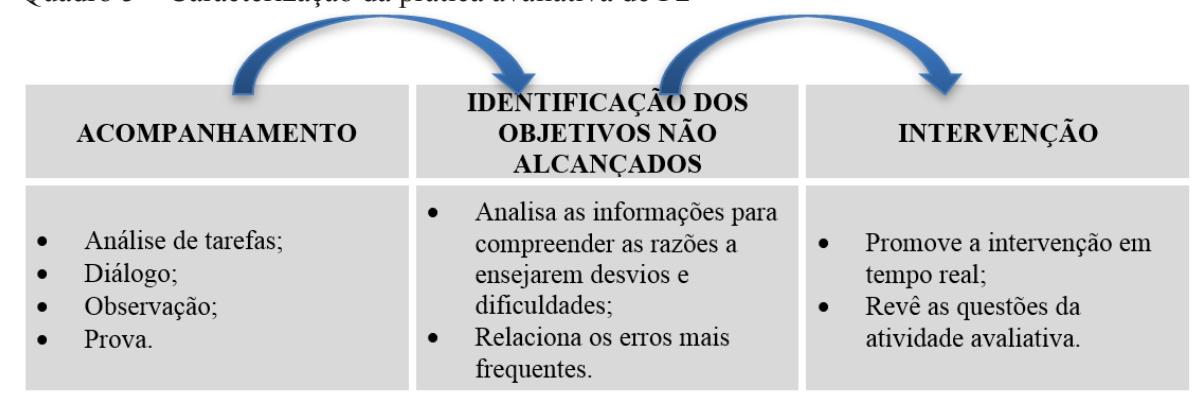

Fonte: os autores.

O desejo de P2 é favorecer a aprendizagem. Essa preocupação é destacada ao relatar: “[...] É preciso utilizar instrumentos diversificados para avaliar, e o texto me permite ter um retorno claro do que o aluno aprendeu.” (informação verbal). Ela esclarece que as produções dos alunos possibilitam realizar uma leitura quanto à qualidade da aprendizagem alcançada por eles, bem como do que ainda ficou falho no processo de ensino e precisa ser retomado.

As Cenas, ao descreverem o trabalho desenvolvido por P2, revelam significativos avanços construídos por ela no campo da avaliação da aprendizagem em Química, progressos que talvez se façam presentes em outras salas de aula, de outras escolas, apesar das dificuldades postas pela realidade de trabalho, da precariedade dos processos formativos, dos impedimentos às discussões colegiadas e da partilha de informações com os pares. Avanços que precisam ser registrados, analisados, discutidos e alavancados para que se multipliquem e conquistem outros espaços. 
Quadro 6 - Descrição de situação avaliativa de P3

Cena 4: A professora inicia a aula explicando aos alunos que apresentará um vídeo relativo
ao tema ácidos e que após a exibição eles realizarão uma atividade valendo nota. Em segui-
da, distribui uma folha contendo as questões. As folhas são distribuídas alternadamente, e a
professora esclarece que contêm questões diferentes. O material do vídeo é composto por um
slide show, com imagens ilustrativas e recortes do conteúdo, contendo: definição de ácido,
exemplos de ácidos orgânicos e inorgânicos, aplicabilidade de alguns ácidos, ácidos mais co-
nhecidos e um experimento demonstrando a carbonização da sacarose.
Concluída a exibição do vídeo, a professora pergunta aos alunos se gostariam de assistir à
apresentação mais uma vez. Eles respondem que sim. O vídeo é reapresentado e, em seguida,
os alunos iniciam a resolução das questões. A maioria o faz individualmente, enquanto alguns
se organizam em duplas para discutirem as respostas. Enquanto trabalham, a professora obser-
va e faz anotaç̃̃es no livro de registro de classe. Fonte: os autores.

$\mathrm{Na}$ Cena 4, a elaboração e apresentação do vídeo pretendeu configurar-se uma "[...] forma diferente de recapitular a matéria" (informação verbal), conforme esclarece P3. Os conteúdos já haviam sido abordados na série anterior, bem como em aulas precedentes, mas precisavam ser revistos - de maneira mais abreviada - antes da resolução da atividade avaliativa, até porque os prazos escolares para a emissão de notas estavam findando e o tempo urgia.

Ao aclarar a finalidade de compor diferentes tipos de provas, P3 diz: " [...] A turma é muito numerosa. Eu não quero os alunos preocupados com as respostas dos colegas, ou mesmo que eles colem, copiando as respostas de outra pessoa. Preciso ver o que ficou ou não do conteúdo trabalhado.” (informação verbal). Tal afirmação é reveladora de que a professora intenta saber o alcance da aprendizagem em construção, bem como localizar insuficiências nesse processo. Ela não impede a partilha de informações, a discussão - o que foi feito pelos alunos que se organizaram em duplas. P3 não impede o questionamento ou a busca de ajuda com os colegas ou com ela, mas espera que as respostas sejam elaboradas por eles, revelando seus percursos de aprendizagem.

Apesar da disposição para o enfrentamento dos problemas de aprendizagem, P3 registra que não é fácil desencadear ações de ajuste do processo de aprendizagem quando as turmas são numerosas. Estudos divulgados por Sampaio e Marin (2004, p. 1214) revelam que "[...] há pistas de que as classes menos numerosas sejam as que conseguem melhores resultados." Ainda, importa lembrar que, afora o número de alunos em sala, os professores duplicam ou triplicam turnos de trabalho em uma ou várias instituições de ensino, "[...] sobretudo quando se trata das séries finais do ensino fundamental e das séries do ensino médio, [...] configurando elemento de forte incidência sobre a precarização do trabalho do professor [...]” (SAMPAIO; MARIN, 2004, p. 1216). 
No momento de comunicação dos resultados aos alunos, P3 informou os erros e anunciou as respostas consideradas corretas. O desejável é que fossem introduzidas situações didáticas diferentes, que permitissem aos alunos revisitarem os conteúdos sob outra perspectiva, envolvidos em outra tarefa. Isso, porém, demanda mais do que o conhecimento específico do conteúdo químico. Exige amplo domínio pedagógico, necessário não somente ao emprego de uma variedade de estratégias a possibilitarem diversas formas de abordagens para um mesmo conteúdo, mas principalmente para a escolha da melhor estratégia.

O tempo conferido para o ensino de Química também é reduzido. São apenas duas horas-aula semanais, geralmente não blocadas. Administrar os conteúdos - preferencialmente em atividades interativas, pautadas em pesquisas e experiências - configura-se quase impossível. Dos 50 minutos de cada aula é preciso subtrair o tempo de deslocamento dos professores de uma para outra sala, os minutos gastos na realização da chamada, o período de acomodação dos alunos e troca de materiais sobre as carteiras. É um tempo perdido. É um tempo de não estudo. Sobra pouco para ser aproveitado em atividades de ensino e aprendizagem. Ao apreciar o cenário geral resta registrar o quanto as professoras conseguem realizar em condições tão adversas e limitantes. 
Quadro 7 - Descrição de situação avaliativa de P3

Cena 5: A professora inicia a aula registrando no quadro de giz a pergunta: "Qual é o conceito de equilíbrio químico?" Um dos alunos responde, enquanto P3 anota no quadro a resposta. Ela, então, diz: "Está certo, mas incompleto." Em seguida, P3 pede aos alunos que busquem na apostila a definição de equilíbrio químico comparando com a definição registrada no quadro e identifiquem o trecho faltante. Os alunos rapidamente a localizam, e a definição é completada no quadro. Ela lança, na sequência, um outro desafio: "Como eu represento esse conceito por meio de uma fórmula, utilizando os símbolos ou a linguagem química?” Ela anota a fórmula no quadro e recapitula o conteúdo, valendo-se de perguntas e registrando e discutindo as respostas. Ao finalizar, a professora distribui uma folha contendo exercícios e explica que essa atividade será realizada individualmente. $\mathrm{P} 3$ pergunta se é necessário ler as questões, e os alunos respondem negativamente. Durante a realização da atividade, um aluno vai até a mesa da professora e lhe pergunta se até aquele ponto da resolução estava tudo certo. A professora observa e diz: "Aqui, nessa parte, você tem que observar a direção do deslocamento do equilíbrio para continuar. Está lembrado?” O aluno diz que sim e volta para a sua carteira, continuando a resolver a atividade.

Depois disso, a professora começou a percorrer a sala de aula, observando o trabalho dos alunos. Em determinado momento, para e conversa com uma aluna, dizendo: "Amanda, observe o quadro! O que você precisa para resolver o exercício está nas anotações que fizemos no início da aula." A aluna atende à professora e, depois de apagar uma parte da resolução, retoma a questão. Em seguida, um aluno chama a professora e lhe pergunta: "A letra b é a correta?" A professora diz: "Leia o que está escrito. A água em ebulição é um processo químico?" O aluno responde: “Não é a b, mas a letra a, pois a água em ebulição é um processo físico e não químico." P3 volta-se para o aluno e diz: "Só é um processo químico quando há transformação da matéria, rearranjo dos átomos, lembra-se?"

Durante o decorrer da aula, os alunos permanecem em silêncio, resolvendo os exercícios enquanto a professora percorre a sala de aula e, por vezes, responde às suas perguntas e/ou faz algum tipo de interferência.

Fonte: os autores.

Durante a aula (Cena 5) - e a consecução da atividade avaliativa -, P3 faz questionamentos, responde a perguntas, esclarece dúvidas, percorre a sala no intuito de acompanhar, em tempo real (HADJI, 1994), as questões e dificuldades que se apresentam. Notadamente, é possível perceber que ela busca mais que manter os alunos engajados e participantes na aula e na execução das tarefas. Seus esforços concentram-se em descobrir impedimentos à aprendizagem, desencadeando ações para a sua superação.

P3 mostra compreender que a avaliação subsidia a ação docente na condução do processo pedagógico. Sua aspiração é que todos aprendam e, ao se posicionar dessa maneira, propicia as condições necessárias para a transposição das dificuldades do percurso e o avanço rumo à melhoria da aprendizagem (ALLAL, 1986; FERNANDES, 2008; HADJI, 1994, 2001; PERRENOUD, 1999). A avaliação, sob essa perspectiva, excede o medir e o controlar para se constituir ferramenta da aprendizagem, a indicar que o mais importante "[...] não é discutir nota, conceito ou qualquer outra 
expressão, mas garantir, de todas as maneiras, o compromisso com a aprendizagem adequada do aluno." (DEMO, 2010, p. 79).

A intervenção intencional favorece a correção dos desvios na aprendizagem discente, recolocando-os "[...] na trajetória que presumidamente leva ao objetivo." (PERRENOUD, 1999, p. 90). P3 auxilia os alunos na execução das tarefas, ora esclarecendo dúvidas, ora fornecendo informações que poderão ser usadas para transpor os obstáculos impeditivos à sua resolução. E, mesmo diante da exiguidade do tempo para ajudar os alunos, percebe-se um agir dedicado, ao apontar os erros e ao empreender esforços para que sejam capazes de superá-los (Quadro 8).

Quadro 8 - Caracterização da prática avaliativa de P3

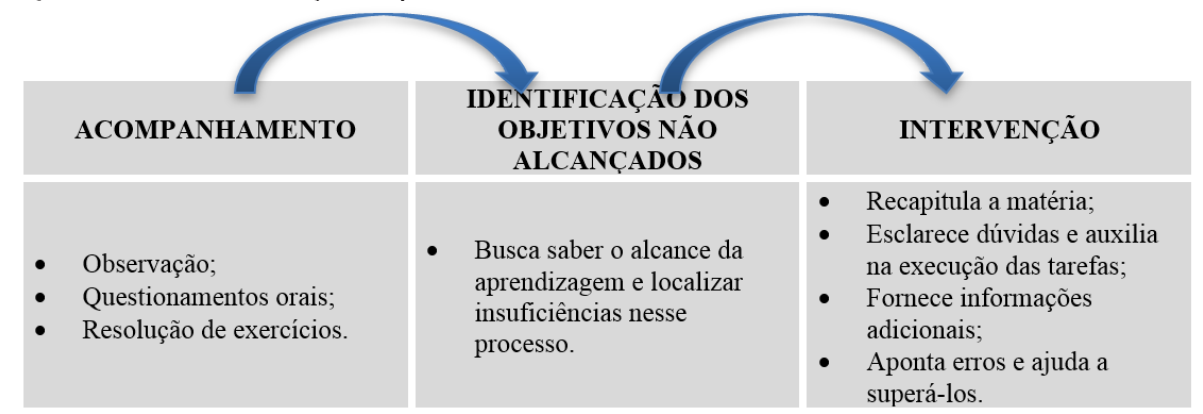

Fonte: os autores.

Para ampliar a compreensão relativamente à forma como as professoras realizaram a avaliação da aprendizagem valendo-se dos erros, foi elaborado um quadro representativo, a partir dos elementos que caracterizam as práticas avaliativas de P1, P2 e P3: acompanhamento, identificação dos objetivos não alcançados e intervenção (Quadro 9).

Quadro 9 - Caracterização da prática avaliativa de P1, P2 e P3

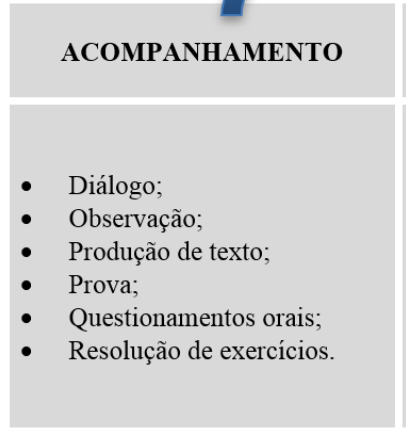

\section{IDENTIFICAÇÃO DOS OBJETIVOS NÃO ALCANÇADOS}

- Analisa resultados;

- Identifica erros;

- Localiza insuficiências no processo de aprendizagem.

\section{INTERVENÇÃO}

- Aponta erros e ajuda a superá-los;

- Esclarece dúvidas e auxilia na execução das tarefas;

- Fornece informações adicionais;

- Realiza interferências em tempo real;

- Recapitula a matéria;

- Revisa questões.

Fonte: os autores. 
Em face das Cenas apresentadas, foi possível considerar que avanços vêm sendo edificados no âmbito da avaliação da aprendizagem em Química. Mesmo ainda ocorrendo a classificação, que enquadra os alunos em determinadas categorias - abaixo ou acima da média, bons ou ruins, etc. -, as preocupações das professoras vão além das qualificações atribuídas. Reconhecer que o desempenho do grupo "foi muito ruim" (P1, informação verbal) em uma tarefa avaliativa não significa "lavar as mãos" e deixar de intervir, corretiva ou formativamente, no intuito de auxiliar os alunos a superarem as dificuldades. As professoras informam - e talvez não devessem fazê-lo - sua insatisfação em relação à aprendizagem demonstrada quando da constatação de acertos e erros, mas, depois, elas intervêm: promovem correções coletivas, passam listas de exercícios, respondem a perguntas, desencadeiam atividades grupais, evidenciando que o compromisso com a promoção da aprendizagem é maior que o zelo com o escore, a hierarquização, a seleção e/ou a exclusão.

O compromisso formativo esbarra, entretanto, nas condições de trabalho. Com diferentes palavras, as três professoras registram o quanto elas interferem na efetivação de ações mais eficientes e pertinentes à promoção da aprendizagem, à retomada do erro e ao ajuste do ensino e da aprendizagem. P1 e P2 sinalizam que, por detrás da incerteza natural a qualquer mudança, estão incutidos outros fatores que acabam por dificultar a prática da avaliação formativa. Segundo P1: "[...] existem outras formas de avaliar, mas numa sala de aula com 35 a 40 alunos, em média, fica tudo bem mais difícil. Além disto, temos poucas aulas e um tempo determinado para ministrar os conteúdos e para fechar as notas." Opinião semelhante é partilhada por P2: “[...] se a carga horária da disciplina fosse um pouquinho maior, seria mais fácil avaliar de outras maneiras." (informações verbais).

Aventurar-se pelas veredas da avaliação, buscando compreender a lógica e os caminhos pelos quais o aluno tem seguido requer dialogar com as inseguranças e os problemas a emergirem do cotidiano escolar e que, às vezes, constituem impedimentos à consolidação do exercício formativo. As preocupações que manifestam são consistentes e reveladoras da precarização à qual estão submetidas, pois, apesar de desejarem proceder de maneira diferente, as professoras participantes ainda não dispõem de subsídios que lhes ofereçam sustentação para empreenderem, com maior segurança, novos percursos. 


\section{TECENDO CONSIDERAÇÕES}

As investigações que nortearam este estudo principiaram com o intuito de apreender como os professores de Química, atuantes em nível médio, concebem e exercitam a avaliação da aprendizagem, principalmente pela forma de abordagem do erro. Empreender essa jornada não foi algo singelo, até porque os primeiros passos na caminhada investigativa apontaram uma realidade diferente da aguardada. As avaliações realizadas pelas professoras participantes deste estudo apresentavam características que as afastavam do viés classificatório e aproximavam-nas do compromisso formativo.

Mais uma vez, foi surpreendente constatar a predominância da avaliação formativa entre as professoras participantes, pois numerosos são os obstáculos que se interpõem à sua consecução: primeiro, a formação inicial dos professores, que é, ou era, ao tempo e área de formação das participantes, mais calcada em modelo diretivo de ensino - centralizado na transmissão, retenção e reprodução de informações; segundo, as condições precárias e "precarizantes" de trabalho terminam por impor obstáculos quase intransponíveis - o tempo de aula é fragmentado em parcelas de 50 minutos, a carga horária de duas horas-aula semanais é insuficiente, os recursos didáticos são escassos, o número de alunos em sala é excessivo para a realização de trabalhos mais participativos, as jornadas de trabalho multiplicam-se em várias escolas ao longo de um mesmo dia, entre muitos outros.

Apesar das condições de formação e de trabalho, as professoras participantes evidenciaram comprometimento com a implementação de ações que favorecessem/propiciassem aos seus alunos a superação das dificuldades identificadas nas atividades avaliativas. Na verdade, esse é um dos aspectos que prendem a atenção e mobilizam ações, ao se advogar a efetivação de avaliação progressivamente mais formativa. Não basta identificar o problema, não é suficiente realizar o diagnóstico, é fundamental conceber e implementar ações pedagógicas que contribuam para promover avanços e superações em termos de aprendizagem e desenvolvimento.

Os relatos e os registros de observação permitiram esboçar alguns aspectos relativos à forma como praticam a avaliação da aprendizagem e à maneira como abordam o erro, no ensino de Química, respondendo ao objetivo norteador da pesquisa. Vislumbrou-se, entre as três professoras: o exercício de uma prática avaliativa menos preocupada com a nota e mais compromissada com a aprendizagem; a predominância da perspectiva formativa de avaliação da aprendizagem, evidenciando uma compreensão que extrapola os limites da prática tradicional, revelando um entendimento de avaliação como um processo mais amplo, que não finda com a correção do instrumento 
avaliativo e a subsequente atribuição de um escore; a utilização de atividades diversas para fazer a coleta de informações levada a termo, intentando realizar o diagnóstico das aprendizagens consolidadas e daquelas ainda em curso, dos mecanismos utilizados pelo aluno para aprender, bem como das dificuldades a permearem ou a atravancarem o processo de aprendizagem; e, ainda, a assunção do erro como indicador, a sinalizar pontos de paragem, reflexão e reconfiguração do processo de ensino e de aprendizagem.

As professoras realizam atividades avaliativas em momentos anunciados, ou seja, com dia e horário previamente definidos. Elas também se valem de tarefas, solicitadas na rotina diária da sala de aula, para analisarem avanços e permanências em termos de aprendizagem e de desenvolvimento de seus alunos. Acompanhar e intervir, a posteriori e em tempo real, é de suma importância para a identificação de carências e a planificação de espaços de intervenção, preferencialmente, pela alteração das estratégias utilizadas para a apresentação dos conteúdos de ensino.

Seguir o caminho trilhado pelos alunos, buscando intervir pedagogicamente de forma a auxiliá-los a avançar, de modo progressivo, no processo de construção do conhecimento e na superação dos obstáculos impeditivos à aprendizagem, anuncia uma visão de erro como indicador diagnóstico a ser observado, analisado e superado. Assim, longe de ser utilizado para punir e constranger, ele é parte integrante do processo - uma manifestação da dificuldade de aprendizagem dos alunos. O erro é reconhecido como um caminho para o acerto, um indicativo dos percursos seguidos pelo aluno na apropriação do conhecimento.

Avaliar a aprendizagem, para as professoras participantes, é identificar problemas e neles intervir para que sejam superados. Não há omissões. Não há acomodamento. Elas não "deixam como está", mas assumem o compromisso de auxiliar os alunos a aprenderem o que ainda não sabem mas podem vir a saber, mesmo que a nota tenha sido atribuída. Importa contribuir para que a aprendizagem seja edificada pela abordagem do erro.

\section{REFERÊNCIAS}

ABRAHÃO, M. H. M. B. (Org.). Avaliação e erro construtivo libertador: uma teoria-prática includente em educação. 2. ed. Porto Alegre: Edipucrs, 2004.

ABRECHT, R. A avaliação formativa. Portugal: Edições ASA, 1994.

AFONSO, A. J. Escola pública, comunidade e avaliação - resgatando a avaliação formativa como instrumento de emancipação. In: ESTEBAN, M. T. (Org.). Avaliação: uma prática em busca de novos sentidos. 2. ed. Rio de Janeiro: DP\&A, 2000. 
ALLAL, L. Estratégias de avaliação formativa: concepções psicopedagógicas e modalidades de aplicação. In: ALLAL, L.; CARDINTE, J.; PERRENOUD, P. A avaliação formativa em um ensino diferenciado. Coimbra: Almedina, 1986.

ÁLVAREZ MÉNDEZ, J. M. Avaliar para conhecer. Examinar para excluir. Porto Alegre: Artmed, 2002.

BARDIN, L. Análise de conteúdo. São Paulo: Edições 70, 1979.

BLOOM, B.; HASTINGS, J. T.; MADAUS, G. F. Manual de avaliação formativa e somativa do aprendizado escolar. São Paulo: Livraria Pioneira de Ciências Sociais, 1983.

BOGDAN, R. C.; BIKLEN, S. K. Investigação qualitativa em educação: uma introdução à teoria e aos métodos. Porto: Porto, 1994.

BRITO, A. S.; SANTANA, R. O.; LOPES, E. T. Professores de memória dos primeiros formandos do curso de licenciatura em Química de Itabaiana. In: COLÓQUIO INTERNACIONAL EDUCAÇÃO E CONTEMPORANEIDADE, LARANJEIRAS, 4., 2010, Laranjeiras. Anais eletrônicos... Laranjeiras, 2010. Disponível em: $<$ http://www.educonufs.com.br/ivcoloquio/cdcoloquio/eixo_04/E4-12e.pdf>. Acesso em: 21 out. 2011.

BROTERO, P. P. A subjetividade na Química impressa por químicos e seu efeito no ensino. 2006. 135 p. Dissertação (Mestrado em Ensino de Ciências)-Universidade de São Paulo, São Paulo, 2006.

CAVALCANTE, D. D.; SILVA, A. F. A. Modelos didáticos de professores: concepções de ensino-aprendizagem e experimentação. In: ENCONTRO NACIONAL DE ENSINO DE QUÍMICA, 14., 2008, Curitiba. Anais... Curitiba, 2008. Disponível em: < http://www. quimica.ufpr.br/eduquim/eneq2008/resumos/R0519-1.pdf>. Acesso em: 12 jul. 2011.

CHIZZOTTI, A. Pesquisa em ciências humanas e sociais. São Paulo: Cortez, 1998.

COSTA, T. S. et al. A corrosão na abordagem da cinética Química. Química Nova na Escola, São Paulo, n. 22, p. 31-34, nov. 2005.

DAZZANI, M. Uma experiência de avaliação da aprendizagem no ensino médio: a participação dos alunos na reconstrução de seus conceitos químicos. 2004. 113 p. Dissertação (Mestrado em Educação em Química)-Universidade de São Paulo, São Paulo, 2004.

DEMO, P. Mitologias da avaliação: de como ignorar, em vez de enfrentar problemas. 3. ed. Campinas: Autores Associados, 2010.

DEPRESBISTERIS, L. Avaliação educacional. Brasília, DF: Senai, 1999. 
ESTEBAN, M. T. Avaliação: uma prática em busca de novos sentidos. 5. ed. Rio de Janeiro: DP\&A, 2003.

FARIAS, C. S.; BASAGLIA, A. M.; ZIMMERMANN, A. A importância das atividades experimentais no Ensino de Química. In: CONGRESSO PARANAENSE DE EDUCAÇÃO EM QUÍMICA, 1., 2009, Londrina. Anais... Londrina, 2009. Disponível em: <http://www.uel.br/eventos/cpequi/Completospagina/18274953820090622. pdf $>$. Acesso em: 17 jun. 2011.

FERNANDES, D. Para uma teoria da avaliação no domínio das aprendizagens. Estudos em Avaliação Educacional, São Paulo, v. 19, n. 1 p. 347-372, set./dez. 2008.

FLICK, U. Uma introdução à pesquisa qualitativa. 2. ed. Porto Alegre: Bookman, 2004.

HADJI, C. A avaliação, as regras do jogo: das intenções aos instrumentos. Porto: Porto, 1994.

HADJI, C. A avaliação desmistificada. Porto Alegre: Artmed, 2001.

HOFFMANN, J. M. L. Avaliação mediadora: uma prática em construção da pré-escola à universidade. Porto Alegre: Mediação, 1993.

HOFFMANN, J. M. L. Avaliação mediadora: uma prática em construção da pré-escola à universidade. 20. ed. Porto Alegre: Mediação, 2003.

HOFFMANN, J. M. L. Avaliar para promover: as setas do caminho. Porto Alegre: Mediação, 2001.

HOFFMANN, J. M. L. Pontos e contrapontos: do pensar ao agir em avaliação. Porto Alegre: Mediação, 2005.

KOSSEBOEHMER, A. C.; FERREIRA, L. H. O processo de reformulação dos cursos de licenciatura em Química nas IES públicas paulistas. In: ENCONTRO NACIONAL DE ENSINO DE QUÍMICA, 14., 2008, Curitiba. Anais... Curitiba, 2008. Disponível em: < http://www.quimica.ufpr.br/eduquim/eneq2008/resumos/R0306-2. pdf $>$. Acesso em: 24 jun. 2011.

LEAL, M. C. A apropriação do discurso de inovação curricular em Química por professores do ensino médio. 2003. 295 p. Tese (Doutorado em Química)-Universidade Federal de Minas Gerais, Belo Horizonte, 2003. Disponível em: < http://www. bibliotecadigital.ufmg.br/dspace/bitstream/1843/FAEC-85NNMX/1/2000000054. pdf $>$. Acesso em: 05 jul. 2011. 
LOPES, A. R. C. A disciplina de Química: currículo, epistemologia e história. Episteme, Porto Alegre, v. 3, n. 5, p. 119-142, 1998.

LUCA, A. G. O Ensino de Química e algumas considerações. Linhas, Santa Catarina, v. 2, n. 1, p. 1-8, 2001. Disponível em: <http://www.periodicos.udesc.br/index. php/linhas/article/viewFile/1292/1103>. Acesso em: 25 jul. 2011.

LUCKESI, C. C. Avaliação da aprendizagem: componente do ato pedagógico. São Paulo: Cortez, 2011.

LUCKESI, C. C. Avaliação da aprendizagem escolar. São Paulo: Cortez, 1995.

LUCKESI, C. C. Avaliação da aprendizagem na escola. Salvador: Malabares, 2005.

MACENO, N. G.; GUIMARÃES, O. M. Concepções de ensino e de avaliação de professores de Química do ensino médio. Revista Electrónica de las Ciencias, v. 12, p. 24-44, 2013.

MALDANER, O. A. A formação inicial e continuada de professores de Química: professores pesquisadores. 2. ed. Ijuí: Unijuí, 2003.

MINAYO, M. C. S. Pesquisa social: teoria, método e criatividade. Petrópolis: Vozes, 1994.

MOREIRA, M. A. O. Avaliação da aprendizagem em Química no ensino médio: a produção escrita como instrumento. 2005. 103 p. Dissertação (Mestrado em Educação em Ciências e Matemática)-Pontifícia Universidade Católica do Rio Grande do Sul, Porto Alegre, 2005.

PACCA, J. L. A.; SCARINCI, A. L. Professores e formadores na formação continuada (atores e diretores na construção de um personagem). Revista Brasileira de Pesquisa em Educação em Ciências - RBPEC, v. 12, n. 1, p. 161-179, 2012.

PERRENOUD, P. Avaliação: da excelência à regulação das aprendizagens - entre duas lógicas. Porto Alegre: Artmed, 1999.

QUADROS, A. L. et al. Os professores de Química relatando problemas enfrentados na profissão. Contexto e Educação, Ijuí, ano 21, n. 76, p. 77-93, jul./dez. 2006.

RABELO, E. H. Avaliação: novos tempos, novas práticas. Petrópolis: Vozes, 1998.

RIBEIRO, E. A. Avaliação formativa em foco: concepções e características no discurso discente. 2011. 140 p. Dissertação (Mestrado em Educação)-Universidade Estadual de Londrina, Londrina, 2011. 
SAMPAIO; M. M. F.; MARIN, A. J. A precarização do trabalho docente e seus efeitos sobre as práticas curriculares. Educação e Sociedade, Campinas, v. 25, n. 89, p. 1203-1225, set./dez. 2004. Disponível em: <http://www.scielo.br/pdf/es/ v25n89/22618.pdf>. Acesso em: 12 ago. 2012.

SANTOS JUNIOR, J. B.; MARCONDES, M. E. R. Identificando os modelos didáticos de um grupo de professores de Química. Revista Ensaio, Belo Horizonte, v. 12, n. 3, p. 101-116, set./dez. 2010. Disponível em: <http://redalyc.uaemex.mx/src/ inicio/ArtPdfRed.jsp?iCve=129516978008>. Acesso em: 27 ago. 2011.

SANTOS, W. L. P.; SCHNETZLER, R. P. O que significa o ensino de Química para formar o cidadão? Revista Química Nova na Escola, São Paulo, n. 4, nov. 1996. Disponível em: <http://qnesc.sbq.org.br/online/qnesc04/pesquisa.pdf>. Acesso em: 10 jun. 2011.

SAVIANI, D. Formação de professores: aspectos históricos e teóricos do problema no contexto brasileiro. Revista Brasileira de Educação, v. 14, n. 40, jan./abr. 2011.

SCHNETZLER, R. P.; ARAGÃO, R. M. R. Importância, sentido e contribuições de pesquisa para o ensino de Química. Revista Química Nova na Escola, São Paulo, n. 1, p. 27-31, maio 1995. Disponível em: <http://qnesc.sbq.org.br/online/qnesc01/ pesquisa.pdf>. Acesso em: 02 jul. 2011.

SCHNETZLER, R. P.; NIEVES, K.; CAMPOS, T. Tendências do ensino de Química na formação e atuação docentes. In: ENCONTRO NACIONAL DE PESQUISADORES EM EDUCAÇÃO EM CIÊNCIAS, 4., 2006, Florianópolis. Anais... Florianópolis, 2006. Disponível em: <http:/www.fae.ufmg.br/abrapec/viempec/viempec/ CR2/p189.pdf $>$. Acesso em: 05 jul. 2011.

SILVA, E. O. Restrição e extensão do conhecimento nas disciplinas científicas do ensino médio: nuances de uma epistemologia de fronteiras. Investigações em Ensino de Ciências, Concórdia, v. 4, p. 51-72, 1999. Disponível em: <http://www. if.ufrgs.br/ienci/artigos/Artigo_ID47/v4_n1_a1999.pdf>. Acesso em: 02 out. 2011.

SILVA, J. L. P. B.; MORADILLO, E. F. Avaliação, ensino e aprendizagem de ciências. Ensaio: Pesquisa em Educação em Ciências, Salvador, v. 4, n. 1, p. 1-12, jul. 2002. Disponível em: <http://150.164.116.248/seer/index.php/ensaio/article/viewFile/46/364>. Acesso em: 15 jun. 2011.

SILVA, P. A.; MAXIMIANO, A. A. A utilização de mapas e redes conceituais como ferramentas de avaliação no ensino de Química. In: ENCONTRO DA PÓS-GRADUAÇÃO INTERUNIDADES EM ENSINO DE CIÊNCIAS, 5., 2010, São Paulo. Anais... São Paulo, 2010. Disponível em: <http://publica-sbi.if.usp.br/PDFs/pd1651. pdf>. Acesso em: 18 ago. 2011. 
SOUZA, N. A.; BORUCHOVITCH, E. Avaliação da aprendizagem e motivação para aprender: tramas e entrelaços na formação de professores. Revista ETD, Campinas, v. 10, p. 204-227, out. 2009. Disponível em: <http://www.fae.unicamp.br/ revista/index.php/etd/article/view/2062/1867>. Acesso em: 20 mar. 2012.

TACOSHI, M. M. A.; FERNANDES, C. Avaliação da Aprendizagem em Química: que concepções de ensino-aprendizagem fundamentam esta prática. In: REUNIÃO ANUAL DA SOCIEDADE BRASILEIRA DE QUÍMICA, 1., 2008, Águas de Lindóia. Anais... 2008. Disponível em: <http://sec.sbq.org.br/cdrom/31ra/resumos/ T1088-1.pdf>. Acesso em: 02 jul. 2011.

TEIXEIRA, J.; NUNES, L. Avaliação escolar: da teoria à prática. Rio de Janeiro: Walk, 2008.

TREVISAN, T. S.; MARTINS, P. L. O. A prática pedagógica do professor de Química: possibilidades e limites. UNIrevista, São Leopoldo, v. 1, n. 2, p. 1-7, abr. 2006. Disponível em: <http://www.unirevista.unisinos.br/_pdf/UNIrev_Trevisan_e_Martins.pdf>. Acesso em: 10 ago. 2011.

VASCONCELLOS, C. S. Avaliação: concepção dialética-libertadora do processo de avaliação escolar. 18. ed. São Paulo: Libertad, 2008.

VASCONCELOS, C. S.; PRAIA, J. F.; ALMEIDA, A. S. Teorias de aprendizagem e o ensino/aprendizagem das ciências: da instrução à aprendizagem. Psicologia Escolar e Educacional, v. 7, n. 1, p. 11-19, 2003.

VILLATORRE, A. M.; HIGA, I.; TYCHANOWICZ, S. D. Didática e avaliação em Física. São Paulo: Saraiva, 2009.

ZABALLA, A. A prática educativa: como ensinar. Porto Alegre: Artmed, 1998.

ZANON, D. A. V.; OLIVEIRA, J. R. S.; QUEIROZ, S. L. O “saber" e o "saber fazer" necessários à atividade docente no ensino superior: visões de alunos de pós-graduação em Química. Ensaio, v. 11, p. 1-23, jun. 2009.

Recebido em: 11 de novembro de 2015

Aceito em: 14 de abril de 2016

Endereço para correspondência: Rodovia Celso Garcia Cid, Km 380, s/n, Campus Universitário, 86057-970, Londrina, Paraná, Brasil, hellainester@gmail.com 